\title{
Risky Meetings Despite Knowledge of the Risk: A Qualitative Study of Young Adults Treated for Chlamydia Infection at a Sexual Transmitted Infection Clinic
}

\author{
Annsofie Adolfsson 1,2 \\ ${ }^{1}$ Department of Dermato-Venereology, Orebro University Hospital, Orebro, Sweden \\ ${ }^{2}$ Department of Health Sciences, Orebro University, Orebro, Sweden \\ Email: annsofie.adolfsson@oru.se
}

How to cite this paper: Adolfsson, A. (2018) Risky Meetings Despite Knowledge of the Risk: A Qualitative Study of Young Adults Treated for Chlamydia Infection at a Sexual Transmitted Infection Clinic. Open Journal of Obstetrics and Gynecology, 8, 572-584.

https://doi.org/10.4236/ojog.2018.86064

Received: April 26, 2018

Accepted: June 5, 2018

Published: June 8, 2018

Copyright $\odot 2018$ by author and Scientific Research Publishing Inc. This work is licensed under the Creative Commons Attribution International License (CC BY 4.0).

http://creativecommons.org/licenses/by/4.0/

\begin{abstract}
The aim of the study was to describe the attitudes to risk behavior among patients diagnosed with a Chlamydia infection at a Sexual Transmitted Infection (STI) clinic. Qualitative interviews face-to-face were conducted with twenty patients, aged 18 - 30 years, with confirmed Chlamydia infections were included. An interview guide was used and the participants described the behavior that had led to the infection. The material was analyzed using qualitative content analysis. Eighteen informants were included and the theme was risk. Recurrent among the informants was risk behavior in sexual relations when using alcohol, while risk behavior in life in general was almost non-existent. Of the 18 informants, sixteen had previously been tested for STIs, and ten had had an STI before. Alcohol consumption emerged as a common denominator among the informants and as a contributor to risk. In contrast, almost none of the informants exposed themselves to any unnecessary risks in life in general.
\end{abstract}

\section{Keywords}

Risky Meetings, Sexually Transmitted Infections, Young Adults, Qualitative Method, Content Analysis

\section{Introduction}

Sexually transmitted infections (STIs) are common in Europe especially among young adults. The World Health Organization (WHO) estimated that in 2008 there were 105.7 million new cases of Chlamydia trachomatis (CT) in the world, 
which was an increase of 4.2 million cases (4.2\%) compared with 2005 [1] [2]. CT is the most common STI in Sweden. In 2002, the number of confirmed cases was 24,691 while it was 37,809 in 2015 . The largest increase was in the age group 15 - 30 years old [3]. The young people are an important group for preventive strategies for STI. They are the most informed group in society on this topic, but do not use their knowledge. The increased prevalence of STIs indicates that people adhere to behaviors with potential risks of contracting an STI, even they have knowledge about these risks. It can be assumed that persons visiting an STI clinic are aware of the existence of STIs.

Symptoms and complications many who are infected with Chlamydia do not notice that they have the disease because the infection often does not give any symptoms at all. Any symptoms may occur mainly with perspiration/itching when kissing, due to inflammation of the urethra. Women who are not treated can cause permanent damage to the ovary with a risk of sterility, and men may have inflammation in the bites. Children may be infected during childbirth and have eye infection or pneumonia if the mother has Chlamydia [3].

Prevention of CT infection is condom that provides relatively safe protection against Chlamydia, and other sexually transmitted infections, if the condom is whole and used throughout the intercourse. Since many can have Chlamydia without knowing about it, and this can lead to problems later in life, it is important that people who have reason to suspect they may be infected allow studying in the healthcare [3].

The World Health Organization (WHO) defined health in its broader sense in its 1948 constitution as "a state of complete physical, mental, and social well-being and not merely the absence of disease or infirmity".

The European policy for health and well-being, Health 2020 is the new European health policy framework. It aims to support action across government and society to: "significantly improve the health and well-being of populations, reduce health inequalities, strengthen public health and ensure people centered health systems that are universal, equitable, sustainable and of high quality".

WHO also has a defined sexual health "Sexual health is a state of physical, emotional, mental and social well-being in relation to sexuality; it is not merely the absence of disease, dysfunction or infirmity. Sexual health requires a positive and respectful approach to sexuality and sexual relationships, as well as the possibility of having pleasurable and safe sexual experiences, free of coercion, discrimination and violence. For sexual health to be attained and maintained, the sexual rights of all persons must be respected, protected and fulfilled".

To understand why the number of infections is increasing, we need to understand what the individuals are thinking and feeling with regards to their sexual behavior.

Love ideology, the ideology which connects sexuality with love has been changed. This change has going on for many years and the result has been a dissolution of "romantic love complex" that governs the forms our intimate rela- 
tionship. Many people have a rising numbers of sexual relationships during a lifetime. Very few people think that sex should only occur in steady relationships. Society has involved with a changed worldview much due to increased migration and communication opportunities worldwide, not least via the internet that opened undisturbed facilities in contact with different kind of people. Many research studies show that young people are influenced in today's society by many different thinking systems where they will find their way of dealing with intimate relationships. Internet is a form of communication that has been introduced in the field of sexuality, which brought about opportunities but also risks. The opportunities are to gain increased knowledge and opportunity to explore their own sexuality. The risks are to meet someone who claims to be someone other than that person in fact. We live in a period of generally higher risk taking in sexual contexts than before [4].

Earlier studies suggest that young people have an adequate knowledge of STIs. Despite this they engage in behavior that is risky in that they do not adequately protect themselves with condoms. A lot of people who contract an STI have felt that they could not contract an infection because they "know and trust their partner". They have had a false sense of security. In the spring of 2006 the Swedish Public Health Institute published a report entitled "Youth and Sexuality" [4]. The report was a summary of 90 research studies which showed that people generally take higher risk in sexual contacts nowadays compared with in earlier decades. It has been shown that young people have a more permissive attitude towards sexual contacts and many engage in riskier behavior when using alcohol [5].

In one internet-based study commissioned by the Swedish government found that in the age group 15 - 29 years, people who lived in more socially deprived communities engaged in riskier sexual behavior and only $50 \%$ of these youths were using condoms when engaging in sexual behavior with new or casual partners. This study also showed that twice as many young adults were infected with STIs compared with the teenage group. The reason for this is that teenagers are provided with free and confidentially distributed condoms by youth health clinics whereas young adults do not qualify for such assistance [6].

A study published in 2016 about condom usage encompassed 4062 participants (1062 were from Sweden). Through comparison with a similar study conducted in 2013 it was determined that condom usage had fallen by $5 \%$ in the age group 21 - 35 years [7].

The aim of the present study was to evaluate the risk behavior of individuals who consulted the STI clinic for an STI-test and were diagnosed with a CT infection.

\section{Methods and Materials}

This study is a qualitative study. The aim of a qualitative study is to describe, explain and make deeper understanding of lived experience. Qualitative research 
involves research where the result does not consist of statistical processes or quantitative approaches. Instead, the results often give descriptions and stories of social, emotional phenomena. The idea is to get an understanding of the characteristics and differences that people describe when they are in different contexts and situations, as well as in different environments. Often the focus is on one or a few phenomenon. Knowledge goes on a deeper level and is often detailed in qualitative studies and can provide a better understanding of phenomena that quantitative findings cannot capture. Qualitative research can be used to investigate people's perceptions, experiences and opinions in relation to a particular phenomenon. You seek understanding and create an image of what is being investigated. The criticism that is often conducted in qualitative studies is the difficulty of generalizability, instead, uses the concept of transferability. Transferability is usually defined as similarity between different contexts. Whether the study is conducted with qualitative or quantitative method, there may be limitations in the transferability. Therefore the selection strategy is equally important whether one performs a quantitative or qualitative study. [8] An example of a qualitative study that shows in a very interesting and good way how a qualitative study can be built up and finally an account of the outcome is Individual experiences following a 6-month exercise intervention: A qualitative study". A thematic structure and analysis, it is possible to follow the entire process step by step [9].

Qualitative research methodology involves a number of different approaches to studying. Some examples of approaches are grounded theory, phenomenology and content analysis. The choice of method is determined by the aim of the study.

The method of this study was qualitative content analysis based on the ideas of Krippendorff [10]. The used method in details was described by Graneheim \& Lundman. Interview guide. The interviews were recorded on tape. The informants were confidential in the tape recordings. The interviews were then transcribed verbatim by a secretary for further analysis [11]. This study included twenty participants' age 18 - 30 years at an STI clinic, which were confirmed to have a chlamydia infection.

The study, conducted from October 2013 to May 2014 used a qualitative interview method [8] [12] and was performed at the STI clinic of the University Hospital in Örebro, Sweden. The study was approved by the Regional Ethics Committee, Uppsala, 2009/322.

\subsection{Participants}

This study included twenty patients age 18 - 30 years at an STI-clinic, who were confirmed to have chlamydia infection. The informants were patients at an STI clinic. Only those confirmed to have a chlamydia infection were asked if they would be interested in participating in the study. Both men and women aged 18 - 30 years were included consecutive. 
The patients were asked about participation by the clinic nurse. They received verbal and written information regarding the study. If a patient agreed to participate, he or she signed a consent form and a time was determined for an interview which took place in a private and confidential room at the STI clinic. Twenty informants were invited to participate and all accepted the invitation. Twenty interviews were conducted but two were lost due to technical problems during recording. The remaining 18 interviews were analyzed according to content analysis [10] [11].

All informants were guaranteed full confidentiality and were informed that they could discontinue participation at any time if they so desired. All participants were completely unknown to the interviewer at the time of the interviews.

\subsection{Data Collection}

The interview guide, see suppl. I, for this qualitative study covered the following areas: reason for the visit, previous STI tests, previous STIs, number of partners in the last year, how the contacts were created in new relationships, if they felt that they exposed themselves to risks in these sexual relations and what the concept of such risks implies. Is risk-taking a part of their life philosophy in general? What was the relationship of alcohol and drugs in the risk-taking behavior? Did alcohol/drugs have any influence on the behavior? Additional questions were about condom usage and about how the participants had received information about STIs. The interviews were recorded on tape. The informants were confidential in the tape recordings. The interviews were then transcribed verbatim by a secretary for further analysis [11]. Background data of the interviewees are shown in Table 1.

\subsection{Data Analysis}

In the study group, sixteen of the patients had previously tested negative for infections. Among these there were three patients who tested themselves regularly online. Five of the patients previously tested had been tested once before, three patients had been tested three times before and five patients had been tested more than three times before.

The number of partners that the patients had been in sexual contact with during the last year varied from one to thirteen see Table 1.

All material was transcribed to text, every word was written. The transcribed interviews were read several times by the author to get a comprehensive impression of the interviews. Codes were written in the marginal. A summary was written of each interview. The codes were written in a code document (Elo \& Kyngas, 2008). And then making search text parts relevant to the aim. The text which has been estimate as relevant for the study was selected in meaning units, which means that the text parts is dividing from different contents. The meaning-bearing units were further developed into groups of codes and abstracted categories. 
Table 1. Back ground data of the informants at an STI clinic in the middle of Sweden.

\begin{tabular}{cccccccc}
\hline Informant & Age & Sex & $\begin{array}{c}\text { Sexual } \\
\text { orientation }\end{array}$ & $\begin{array}{c}\text { Number of sexual } \\
\text { partners last } 12 \text { months }\end{array}$ & $\begin{array}{c}\text { Previous } \\
\text { STI tests }\end{array}$ & $\begin{array}{c}\text { Previous } \\
\text { STIs }\end{array}$ & $\begin{array}{c}\text { Reason for } \\
\text { contact }\end{array}$ \\
\hline 1 & 23 & F & Hetero & 13 & Yes & Yes & Prompted \\
2 & 21 & F & Hetero & 2 & No & No & Prompted \\
3 & 24 & M & Homo & $5-6$ & Yes & No & Symptoms \\
4 & 28 & F & Hetero & 3 & Yes & Yes & Prompted \\
5 & 20 & M & Homo & 5 & No & No & Check-up \\
6 & 19 & F & Hetero & 4 & Yes & No & Check-up \\
7 & 25 & F & Hetero & 3 & Yes & No & Prompted \\
8 & 23 & F & Hetero & 6 & Yes & Yes & Check-up \\
9 & 24 & F & Hetero & 12 & Yes & Yes & Check-up \\
10 & 28 & F & Bisexual & Unsure & Yes & Yes & Check-up \\
11 & 29 & F & Hetero & 6 & Yes & Yes & Symptoms \\
12 & 21 & F & Hetero & 12 & Yes & No & Prompted \\
13 & 23 & F & Hetero & $4-5$ & Yes & Yes & Check-up \\
14 & 27 & F & Hetero & 3 & Yes & No & Check-up \\
15 & 26 & M & Hetero & Do not know & Yes & Yes & Prompted \\
16 & 29 & M & Hetero & 1 & Yes & No & Prompted \\
17 & 28 & F & Hetero & 3 & No & Check-up \\
\hline 18 & 24 & F & Hetero & 6 & No & Check-up \\
\hline
\end{tabular}

The categories describe the manifest content of the transcripts of all the interviews. To describe the latent content of the interviews, subthemes were formed and then finally the theme was identified. The analysis of the transcript was done using qualitative content analysis based on the Graneheim and Lundman method [11]. See Table 2.

\section{Results}

The resulting theme of the study is "Risk-taking in sexual behavior". The theme is made up of five sub-themes, Meeting unfamiliar people at a bar or online; The resulting relationship is casual and they will probably not meet again; When alcohol is in the mix, judgment is impaired; condoms are embarrassing and awkward; Drugs use was minimal among participants in the study, but more common in society, see Table 2.

\subsection{Meeting Unfamiliar People at a Bar or Online}

The informants in the study made initial contact with potential sex partners in a variety of ways. Contacts were made through social network, through friends and through acquaintances at parties or bars. Another major factor these days is online contacts with strangers. 
Table 2. Examples of meaning-bearings units, codes, categories, sub-themes and themes from the content analysis of the interviews.

\begin{tabular}{|c|c|c|c|c|}
\hline Meaning-bearing unit & Code & Category & Sub-theme & Theme \\
\hline $\begin{array}{l}\text { Making first contact online, } \\
\text { at parties, pubs and bars, } \\
\text { most often at a bar }\end{array}$ & Contact & $\begin{array}{l}\text { Contact with } \\
\text { strangers }\end{array}$ & $\begin{array}{l}\text { Meeting unfamiliar people } \\
\text { at a bar or online. }\end{array}$ & \\
\hline $\begin{array}{l}\text { Unknown contacts may } \\
\text { entail risks that could have } \\
\text { negative consequences }\end{array}$ & $\begin{array}{l}\text { Sexual } \\
\text { relations }\end{array}$ & STI & $\begin{array}{l}\text { The resulting relationship is } \\
\text { casual and they will } \\
\text { probably not meet again. }\end{array}$ & \\
\hline $\begin{array}{l}\text { Easier to make contact when } \\
\text { intoxicated and less inhibited }\end{array}$ & Alcohol & $\begin{array}{l}\text { Judgment } \\
\text { impaired }\end{array}$ & $\begin{array}{l}\text { When alcohol is in the mix, } \\
\text { judgment is impaired. }\end{array}$ & $\begin{array}{c}\text { Risk-taking in } \\
\text { sexual }\end{array}$ \\
\hline $\begin{array}{l}\text { Easier not to use a condom } \\
\text { to avoid a debate about using } \\
\text { one }\end{array}$ & $\begin{array}{l}\text { Condom } \\
\text { use }\end{array}$ & $\begin{array}{l}\text { No } \\
\text { motivation } \\
\text { to } \\
\text { use condom }\end{array}$ & $\begin{array}{l}\text { Condoms are embarrassing } \\
\text { and awkward. }\end{array}$ & behavior \\
\hline $\begin{array}{l}\text { Drug use not a factor in the } \\
\text { sexual relations of the } \\
\text { participants }\end{array}$ & Drugs & $\begin{array}{l}\text { Deterrent } \\
\text { effects }\end{array}$ & $\begin{array}{l}\text { Drug use was minimal } \\
\text { among participants in the } \\
\text { study, but more common in } \\
\text { society. }\end{array}$ & \\
\hline
\end{tabular}

"This superficial network is indeed a gamble and a crap shoot. There is tremendous risk with this sort of hook-up."

"Risk is not something you are consciously thinking about or aware of or even care about, but that is the nature of the risk in sexual behavior. It's when your guard is down that something can happen."

Meeting someone at a bar is not the ideal way to get to know someone. Being at a bar probably means that both parties are under the influence of alcohol. Many of the participants mentioned that the best way to meet someone is through mutual friends or acquaintances. However, they would forget their own advice and engage in risky sexual behavior or unprotected sex with strangers and afterwards they would often second-guess such actions.

"What was I thinking ..."

This is the nature of sexual behavior when alcohol influences inhibition. It is happening in the moment and feelings are running on overdrive.

"It is what it is ... it just happens. But before it happens I know that it isn't so smart."

Most of the interviewees confessed that they do take risks. People who are aware of risks and take them anyway are more likely to accept the consequences of their risky behavior. Some of the participants exposed themselves to more risky behavior and some of the participants were inclined to take smaller risks, but all were aware that they were taking risks and took them anyways.

\subsection{The Resulting Relationship Is Casual and They Will Probably Not Meet Again}

The interviewees explained that if, when they first meet a person, they are inclined to trust their new contact, and they will see them as a lower-risk sexual 
partner. If they are unsure about the person and get funny vibes from their potential contact, they view them as a bigger risk. Alcohol can influence this in the opposite direction. The interviewees were very clear in that they did not think the same way when they were drinking as they did sober. The sexual tension in such situations involves a different kind of thinking or an absence of thinking. They were aware of the risks but took them anyway, recklessly and in the heat of the moment.

"Risk is something that can happen but it doesn't need to be negative. The risk is a consequence of something. When talking about risks, it is important to talk about the same thing."

"You are seeking acknowledgement."

Some of the interviewees explained that the riskier the behavior that they were involved the more uncomfortable the consequences could be. As woman relates:

"It gets a bit dicey when you end up with somebody who does not understand that when you say no ... it means no."

Some of the interviewees related that they had sex with people who were completely unknown to them and some also had a very poor idea of how many sexual partners they had been within the last year.

"Several partners, I met only once."

Other interviewees described "getting a high when taking risks." The interviewees might be more cautious in their approach to driving a car than to possibly getting infected with chlamydia. In the back of their minds they would be rationalizing, thinking that the infection is curable with antibiotics.

"Antibiotics can cure a dose of Chlamydia ..."

\subsection{When Alcohol Is in the Mix, Judgment Is Impaired}

All interviewees drank alcohol and were well aware of the risks with consuming alcohol. Only three of the 18 interviewees felt that they had low alcohol consumption. Each had their own rationale and reasons to justify their level of alcohol consumption. Even those with a high level of consumption were aware of the additional risks associated with high consumption.

One of the justifications was that everyone else was doing it and they were therefore going along with the crowd. One interviewee admitted to working specifically to afford buying alcohol and participating in nightlife and social activities.

"If you are drunk you are obviously not thinking very clearly and, you can end up taking risks."

The interviewees acknowledge that they put themselves in a compromising situation by being under the influence of alcohol. When sober, they would not even consider undertaking the behaviors they did when drinking.

Interviewees described that they would regret making the decision to have sex in a drunken state. These people were clear that having sex with strangers represented risky behavior. Even though they were normally aware that this sort 
of risk-taking wasn't a good idea, in the drunken state and the heat of the moment they went with their impulses.

"You are in the heat of the moment and you see how far it goes. It s fun ... exciting."

These types of situations illustrate what happens when individuals go along with the crowd by consuming alcohol and engaging in risky sexual behavior. Judgment is impaired and behavior is influenced accordingly.

"When you' re drunk, you don't use a condom, thus taking more risks."

Only one of the interviewees said that they used alcohol because it tasted good especially in social contexts, such as sharing a meal. The person with the lowest consumption described their usage as:

"I drink a little alcohol when I hang out with nice people."

\subsection{Condoms Are Embarrassing and Awkward}

When it comes to information about sexually transmitted diseases, it appears that all of the informants had received information at one time or another, from either school, parents or friends about the importance of condom use as protection against sexually transmitted diseases.

Choosing not to use a condom is risky behavior. Most of the interviewees did not use condoms. The majority of the interviewees considered condom use to be a matter of course, but they had still somehow contracted chlamydia. The explanations for not using condoms varied and the most frequent were that it was embarrassing and awkward, not to mention there was a degree of difficulty. The combination of the awkwardness of using a condom and the embarrassment in suggesting it sometimes discouraged actual use of condoms.

"Nobody is proposes use of a condom because it s embarrassing."

"The condom thing ruins the moment and you basically don't care when you' re drunk."

"It is what it is and it is pretty obvious, you get carried away even though it is not so smart. But when you are drinking it is easier to just not bother about it."

Someone described that they would be forced to argue if they wanted to use a condom and this would have the effect of ruining the moment. Those who insist on using a condom put themselves at risk of being rejected because of it. Another informant said that if she was going to have sex abroad, she would always use a condom.

"I am convinced that condoms make a difference but it isn't always the actual case realistically.

I usually regret it the day after if I didn't use one."

Throughout the interviews the interviewees maintained that when alcohol was in the mix, when they became intoxicated, judgment went out the window and condom usage did not occur.

\subsection{Drug Use Was Minimal among Participants in the Study, But More Common in Society}

The participants in the interviews did not use drugs. Most of them maintained 
that they had never used drugs, some admitted to having experimented but were not current drug users. The interviewees drew a line between their high alcohol consumption and their decision not to use drugs.

\section{Discussion}

The new European health policy framework aims to support action across government and society. But how can we in everyday care contribute to reducing ill health. Health care professional meeting with people is important in the work of awareness raising a risk behavior. Prevention work is invaluable. Communication between people at all levels of care can contribute to a change in lifestyle and living conditions. There is no time a person is as receptive as when one is concerned. Social media is good and innovative in many ways, but it can also contribute to unexposed influences that can lead to the influence of young people who are building a platform in adulthood. Everyone is not ready and susceptible to dealing with it in a sufficiently mature and selected way, but sometimes exposes oneself to risks without thinking about the consequences.

The common factor among the interviewees, who had all contracted chlamydia was risky sexual behavior. The informants were aware that having unprotected sex with people they didn't know or didn't know well was risky sexual behavior as also described by Carré, H. [13]. The result in the study shows that in the bar and pub environment, where alcohol is being consumed in excess risky behavior increases with alcohol use. Causal sex under the influence of alcohol was a way for the informants to get personal acknowledgement.

In recent decades, since the outbreak of the HIV virus, research has increased regarding sexual risk-taking behavior among young people [14] [15]. A large part of this research is quantitative in nature and involves mapping out the behavior of young people. Common denominators in risky sexual behavior are sporadic condom use, casual sexual relationships and a lower age of sexual debut. Statistics available about sexually transmitted disease and unwanted pregnancy confirm that many young people are practicing unprotected sex "One night stands" [6] [16].

Although it appears that most everyone is aware of the benefit and value of using condoms as protection, more than half do not always use them. Many feel a reason not to use them is inconvenience or perceived reduction in the pleasure of having sex [17]. Alcohol consumption has a big influence on the decision-making process regarding whether or not to use a condom. It appears that it only takes a drink or two to influence the judgment toward the view that it isn't necessary to use one. The results of this study are consistent with other studies showing that condom usage has decreased among young adults.

In a Swedish study performed at Gothenburg University called Ung KAB 09, it was found that young adults are taking just as many risks as teenagers. Young adults in this case have less access to contraceptives as the teenagers are provided free contraceptives through the health care system [6]. In a recent study by an 
organization in Sweden, RFSU, that provides information on sexual behavior to Swedish people, it was found that condom usage had fallen from $48 \% 2013$ to $43 \% 2016$ in the age group 21 - 35 years [7]. According to the report "Alcohol and sexual risks taken" there is a correlation between lower education levels, unemployment and instances of unprotected anal intercourse. It was also found that people who are in the immigration process are vulnerable to sexually risky behavior [5] Among exchange students from a Swedish University a cross-sectional study was conducted based on web survey with questions about sexual behavior, self-esteem and psychological well-being, 136 participants. They rated their health as good and the majority of them participated in information sessions that addressed preventive efforts on HIV/STI and safer sex before departure but sexually risk behavior during exchange studies was reported [18].

There was no difficulty in recruiting participants. All respondents accepted to participate. 18 interviews were analyzed and the results were used as the basis for this study. The theme was "risk-taking in sexual behavior". The theme is built up by subtheme, "Meeting unfamiliar people at a bar or online", "The resulting relationship is causal and they will probably not meet again", "When alcohol is in the mix, judgment is impaired", "Condoms are embarrassing and awkward", "Drug use was minimal among participants in the study, but more common in society". One positive aspect of the qualitative interview method is that it makes it possible for the interviewee to open up and reveal things about their personal and private life.

Generally speaking the participants took very few risks in other situations in life. Most described themselves as cautious and responsible. For instance, they discussed their concern about driving safely among other aspects of their everyday lives. Their sexually risky behavior under the influence of alcohol was in contrast with their otherwise conservative approach to risk in general. An individual sex life is of a private nature. There is no outside judgment on the behavior of the moment.

The interviewees were more sensitive to their risk-taking when they were in the public eye, when they were being perceived by their surroundings. In the interviews, they were very open and honest about their sex lives and their decision-making processes.

The limitations in the study are that only informant exposed and identified with Chlamydia infection were interview about their risk behavior. All data were collected in Sweden in a middle size town.

\section{Conclusion}

The results of this study confirm that alcohol consumption is a major factor in the interviewees' propensity for risky behavior in sexual relations. Comparatively speaking their risk-taking in other life, a large influence on whether or not they might expose themselves to environments allowed or encouraged such risky behavior. 


\section{Acknowledgements}

The study was supported by the Research Committee of Region Örebro County and the Department of Dermato-Venereology, Örebro University Hospital.

\section{References}

[1] WHO-World Health Organization (2012) Dept. of Reproductive Health and Research.

[2] Zarb, P., Coignard, B., Griskeviciene, J., Muller, A., Vankerckhoven, V., Weist, K., Goossens, M.M., Vaerenberg, S., Hopkins, S., Catry, B., Monnet, D.L., Goossens, H., Suetens, C., National Contact Points for the ECDC Pilot Point Prevalence Survey Collective and Hospital Contact Points for the ECDC Pilot Point Prevalence Survey Collective (2012) The European Centre for Disease Prevention and Control (ECDC) Pilot Point Prevalence Survey of Healthcare-Associated Infections and Antimicrobial Use. Eurosurveillance, 17, Article ID: 20316. https://doi.org/10.2807/ese.17.46.20316-en

[3] The Public Health Agency of Sweden (2015) http://www.Folkhalsomyndigheten.se

[4] Forsberg, M. (2006) Ungdomar och sexualitet. En Forskningsöversikt år 2005. Statens Folkhälsoinstitut. http://www.fhi.se

[5] The Swedish Institute for Infectious Disease Control (SMI) (2011) Alcohol and Sexual Risks Taken. http://www.smittskyddsinstitutet.se

[6] Tikkanen, R., Abelsson, J. and Forsberg, M. (2009) Ung KAB 09, Methodological Considerations Regarding the 2009 Youth and Sexually Survey in Sweden. http://www.folkhalsomyndigheten.se/publicerat-material

[7] Information (RFSU) https://www.rfsu.se/om-rfsu/om-oss/in-english/

[8] Kvale, S. and Brinkmann, S. (2009) Interviews: Learning the Craft of Qualitative Research Interviewing. Sage Publications Inc., Los Angeles.

[9] Staveborg, E., Kerkelä, E., Jonsson, L., Lindwall, M. and Strand, J. (2015) Individual Experiences Following a 6-Month Exercise Intervention: A Qualitative Study. International Journal of Qualitative Studies on Health and Well-Being, 10, Article ID: 26376. https://doi.org/10.3402/qhw.v10.26376

[10] Krippendorff, K. (1980) Content Analysis: An Introduction to Its Methodology. Sage Publications Inc., London.

[11] Graneheim, U. and Lundman, B. (2004) Qualitative Content Analysis in Nursing Research: Concepts, Procedures and Measures to Achieve Trustworthiness. Nurse Education Today, 24, 105-112. https://doi.org/10.1016/j.nedt.2003.10.001

[12] Svensson, P. and Starrin, B. (1996) Qualitative Studies in Theory and Practice. Studentlitteratur, Lund.

[13] Carré, H. (2010) Who's at Risk of Catching Chlamydia trachomatis? Identifying Factors Associated with Increased Risk of Infection to Anable Individualized Care and Intervention-Identifying Factors Associated with Increased Risk of Infection to Enable Individualized Care and Intervention. Medical Dissertations, Umeå University, Umeå.

[14] Lindberg, M. and Scott-Jansson, L. (1996) Smittad Med STD Trots Preventiv Kunskap. En fördjupnings-och beteendestudie av unga patienter med klamydiainfektion. Örebro Läns Landsting.

[15] Fenton, K.A., Mercer, C.H., Johnson, A.M., Byron, C.L., Mc Manus, S., Erens, B., et 
al. (2005) Reported Sexually Transmitted Disease Clinic Attendance and Sexually Transmitted Infections in Britain: Prevalence, Risk Factors, and Proportionate Population Burden. Journal of Infection Diseases, 191, 127-138.

[16] Christianson, M., Johansson, E., Emmelin, M. and Westman, G. (2003) One-Night Stands-Risky Trips between Lust and Trust: Qualitative Interviews with Chlamydia Trachomatis Infected Youth in North Sweden. Scandinavian Journal of Public Health, 31, 44-50. https://doi.org/10.1080/14034940210134158

[17] Carré, H., Lindström, R., Boman, J., Janlert, U., Lundqvist, L. and Nylander, E. (2011) Asking about Condom Use: A Key to Individualized Care with Screening for Chlamydia. International Journal of STD/ AIDS, 22, 436-441. https://doi.org/10.1258/ijsa.2011.010481

[18] Petersson, C., Peterson, U., Swahnberg, K. and Oscarsson, M. (2016) Health and Sexual Behavior among Exchange Students. Scandinavian Journal of Public Health, 44, 671-677. https://doi.org/10.1177/1403494816665753 